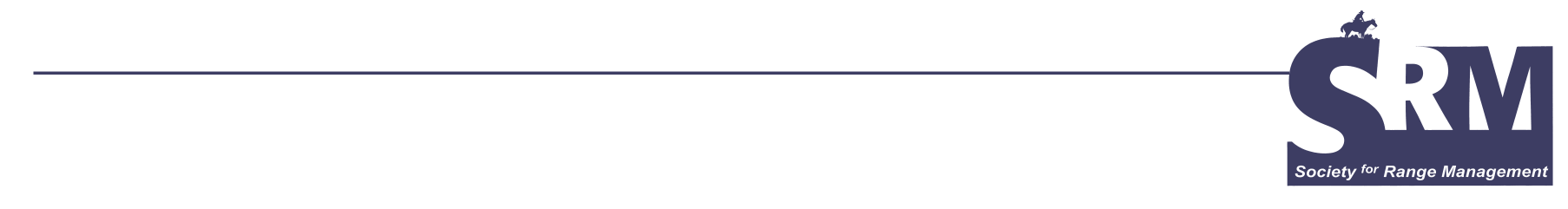

\title{
Riparian Grazing Ideas and Alternatives
}

\section{When cattle graze in riparian areas, creek fencing should be the last choice.}

\section{By Chuck Perry}

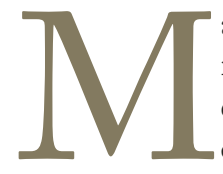

anagement of riparian areas and stream channel features to maintain their development, diversity, and condition has become the focus of much attention. Minimizing livestock grazing impacts to these areas challenges many ranchers and becomes critical when dealing with wildlife or fish habitat and water quality issues. The most commonly suggested

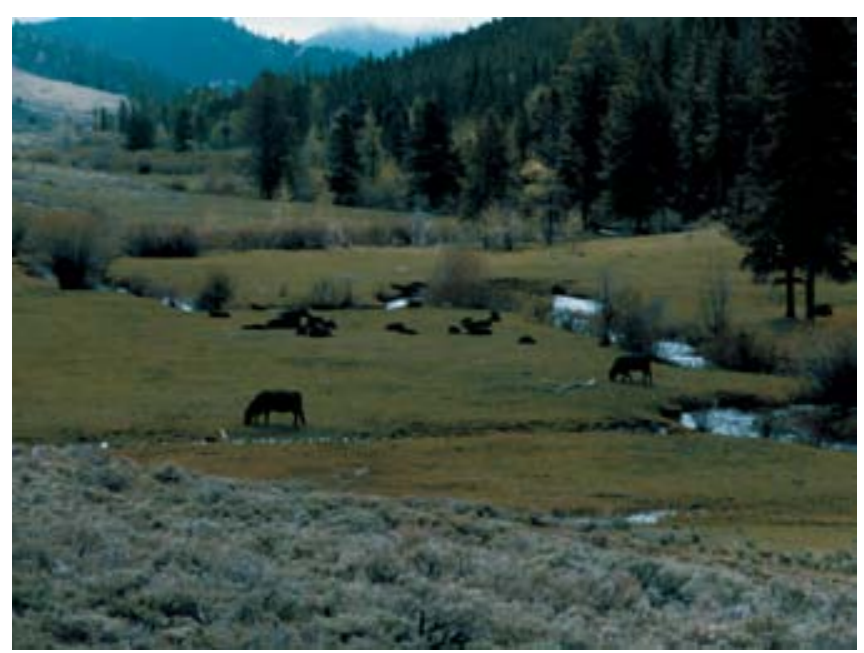

Grazing in stream bottoms does not have to be destructive. But it does need to be carefully managed to maintain or improve riparian features. Note dense vigorous herbaceous vegetation in the floodplain and developing woody vegetation along the stream channel. File photo courtesy of Wayne Leininger. alternative, stream fencing, may not be either feasible or the best alternative in many cases. The list below discusses some grazing management ideas that do not always include permanently fencing out the stream and riparian area. These ideas are based on my observations of ranchers' innovations during the past 30 years.

\section{Structural Improvements}

1. Fencing must remain as a possible alternative. However, it should be the last choice, after every other management option has been considered. If you choose fencing, it should not be built just outside the riparian area. This will lead to additional problems and costs. Build it as topography dictates, but well out of bottoms and away from any area that may be flooded in spring. This will protect the fence and reduce maintenance. Consider using smooth wire to ease construction and reduce maintenance. Temporary fences will sometimes work for short grazing periods or to protect specific sites.

Fence to create riparian pastures that can be specifically managed and possibly used for short periods when stream damage will probably not occur, for example in early spring (see below). The fence will protect stream and riparian features most of the time, but will also allow some managed grazing use for rancher benefit and site enhancement.

2. Develop off-stream livestock water in as many places as possible within each pasture with a riparian and stream damage concern. Make these sites easy for animals to use: 
moderate or gentle slopes leading into the watering site, a flat gravel or nonmuddy area around water, and a tank or other water handler that keeps water clean; for example, possibly provide a shade structure near the tank. Make off-stream watering sites more convenient, attractive, and easier to use than stream water.

3. On streams with steep or open dirt banks, which are vulnerable to livestock damage during muddy conditions, create a "hardened crossing." Develop a gentle slope down to the stream on both sides. Dump rock on these stream approaches and across the stream. Use large enough material that high water will not move it in spring, but small enough that it makes a good surface for animals to walk on. This will do several things: ease livestock access to the stream at that point, keep the water clean, prevent silt and erosion, allow good animal footing to drink or cross, and minimize bank trampling in other areas. When putting rock into a stream, do not create a fish passage problem or restrict water flow. It's usually better to keep the stream bottom elevation the same. Build "hardened crossings" at sites animals currently use to water or cross a stream. Space them at about one-fourth- to one-half-mile intervals. Get proper permits! If a stream channel has rocky shores that currently limit animal access, "hardened crossings" may not work. However, if watering sites are muddy, some rock may improve both water quality and livestock preference. In the right situation, "hardened crossings" are usually low cost, result in improved riparian vegetation, and help keep animals away from vulnerable stream banks in other areas, without fencing.

4. The reverse of hardened crossings uses a culvert to bridge a stream and thus reduce siltation and erosion. This may need to be combined with off-stream water. Providing an easy way for cattle to cross a stream without needing to negotiate steep banks or mud can result in protecting the stream and riparian vegetation. Use a large enough culvert to handle spring flows. Permits for this action may be required.

5. On wooded, semiwooded, or densely brushed streams, a mechanical barrier may work in places where animals are causing damage. Trees or logs felled along a stream must be large enough that animals cannot easily step across them and overlapped enough that the animals cannot just go around the barrier. They must be situated to prevent animals from walking along the stream bank. If a stream has spring floods, these barriers will probably move or change, so they may not be a permanent arrangement.

\section{Planning}

1. Pastures with creeks and riparian areas susceptible to livestock damage should be grazed in the spring. Early spring is usually better than late spring. Upland forage in the pasture has high palatability in early spring, days are cooler, animals require minimum water, shade is not a factor, and insect populations are low. When early use is combined with riding it may be fairly easy to keep animals away from streams. Winter use may also work well. Leave enough stubble height to trap sediments during high spring flows. Practice fairly rapid rotation through pasture systems with streams. Try to prevent long, concentrated grazing use near streams at any time. Develop a management strategy that results in higher plant vigor, rapid plant regrowth, and higher forage production in upland areas also.

2. Develop a plan that provides for grazing streams and riparian pastures in early spring, and grazing pastures with other water sources in late spring and summer. If this is not possible, then try planning for short grazing use periods in units with susceptible riparian areas. Animals are very difficult to keep away from stream or riparian sites in summer or a dry fall. Short grazing periods will result in adequate stubble height in riparian areas and allow strong, rapid forage regrowth. If necessary, rearrange pasture fencing or use temporary fencing to allow some type of rapid rotation management.

3. Locate both salt and nutrient blocks well away from a stream. Ideally these should be put in areas of high quality and plentiful forage and not too distant from an offstream water source. Try to create conditions that are desirable for livestock so they will want to go there. However, don't leave animals in one location for long periods. This will overgraze the site, reduce plant vigor, slow regrowth, and result in less total forage. Move nutrient blocks and salt on a regular basis to encourage upland grazing, protect site forage production potential, and keep animals gaining. Provide hay or some alternative food source when forage is low and palatability is poor. At times this may be impractical. However, in certain situations and when resources are available, this may encourage animals to remain longer at a site that meets their needs in summer and not move back to riparian areas as quickly.

\section{Animal Management}

1. Riding, to move animals away from water, works in many cases. However, it's more than just moving animals away. They must be moved to areas with abundant and palatable ungrazed or regrown forage that is more attractive than sites near water. It also helps to have off-stream water available. If every time a rider moves animals they go to good forage sites, they will learn to seek out these upland areas. Riding does little good if animals are moved only a short distance away from water and they don't find desirable conditions. In this situation, they will be back to the stream very quickly. Riding must be done often to be effective, depending on conditions. It may take several years, but animals can be conditioned to seek good upland forage areas.

2. Burn, mow, intensively graze (many animals for short time), or in some other way remove some old, ungrazed forage on suitable sites away from streams. This will make palatable regrowth more accessible and desirable for livestock and attract their use. Do not allow continual overuse of areas away from a stream that you want animals to select. 
Overgrazing will reduce plant vigor and slow regrowth, even into the following year. Plants grazed lightly to moderately will produce rapid regrowth and more total forage.

3. Fertilizer applied in fall or early spring may increase the production, nutrition, and palatability of forage plants and extend their green period later into spring or early summer. These effects could attract animals away from streams, even when other upland forage begins to mature. Treat the best areas; they need good soil, high forage production potential, good perennial forage plant cover, minimal weed problems, and enough precipitation or soil moisture for plant growth and they must be easily accessible to livestock.

4. Consider using animal selection as a tool. Remove individuals that constantly hang around the creek and keep those that tend to graze the uplands more readily. This may be a slow process but it can work over time and may result, long term, in much less effort in managing livestock to minimize riparian impacts.

5. Consider keeping some older animals with each herd. These animals know where off-stream forage and water sites are located, and will tend to lead the rest out to upland areas they have used before. Also, if yearlings are part of a ranch program, try using these younger animals in pastures with riparian zones. Their ability and inclination to move around and cover the whole pasture may avoid some concentration problems. These animals may also be easier to train, by herding, to seek out high-quality forage away from streams.

\section{Watch and Learn}

The best method of all is to carefully observe conditions and think. How are current grazing practices affecting stream and riparian conditions? If animals concentrate along streams and are causing stream bank damage problems, what might be done to change this? Carefully lay out goals for pastures with stream and vulnerable riparian areas. Then inventory the current situation, the factors at work, and the resources available to make changes. This will define where you want to go and what there is to work with. Consider traditional cattle management methods, but don't be constrained by them. Also, consider the ideas listed above and other innovative possibilities no matter how impractical they appear at first. Try management practices separately and in various combinations that seem to fit your conditions, and that might keep animals from concentrating along a stream. Monitor the results; annual photos are an easy way to objectively follow changes. Use this information to make additional changes or adjustments that may work better. Keep asking yourself if your management practices are working and how they can be made more effective to meet your goals. These lists are only a starting point to stimulate thinking. Ranch managers trying their own grazing management alternatives will add many ideas and practices to these suggestions.

Within the context of site features, conditions, resources, and time, what works best to accomplish both business and natural resource objectives will probably differ from site to site. Select actions that fit individual criteria and develop productive pasture conditions that result in other multiple benefits. Learn about other ranchers' experiences and discuss ideas or possibilities with knowledgeable people; a positive approach to the problem may emerge. However, in order to have a high probability of success, the final decision to implement practices needs to be made by the individual rancher. Monitor management action results and be ready to adjust, when necessary, to move toward your goals.

Editor's Note: Chuck Perry is an SRM Certified Range Management professional who has worked for the Washington Department of Fish and Wildlife and is now in private rangeland consulting. The information in the manuscript was obtained from ranchers and observations over $35+$ years. 